\title{
Earth's Obliquity Oscillations Can Influence Climate Change by Driving Global Volcanic Activity
}

\author{
Viacheslav. A. Bezverkhnii \\ Laboratory of Geophysical Fluid Dynamics, A.M. Obukhov Institute of Atmospheric Physics, \\ Russian Academy of Sciences, Moscow, Russia \\ E-mail: vabezv@ifaran.ru
}

\begin{abstract}
Spectral and wavelet analysis reveal the chain of close phase and coherence relationships at the obliquity frequency in variations of the tilt of the Earth's rotational axis (obliquity), frequency of large volcanic eruptions $\left(E_{f}\right)$ along the Pacific Ring of Fire, and climate characteristics, represented by the relative content of oxygen-18 $\left(\delta^{18} \mathrm{O}\right)$ in the calcite of fossil benthic foraminifers (prominent LR04 stack), Antarctic and Greenland ice core data. The links revealed show that powerful 41,000-year rhythms in the Plio-Pleistocene climate variations can be caused by geophysical and geochemical effects of global volcanic activity which is induced by the forced obliquity oscillations.
\end{abstract}

Keywords: The Earth's obliquity, volcanic activity, stable isotopes, climate; wavelet, spectral analysis.

\section{Introduction}

Strong past climate changes appear to be linked to variations in the Earth's obliquity $(\varepsilon)$ as well as to other orbital variations (mainly precession and eccentricity). A major cause of orbital-scale changes in the global and regional climate changes remains under debate since the XIX century [1, 2] (see e.g. [3]). Geologic and climatic discoveries of the past few decades give impulse to exploring mechanisms that could translate orbital factors to changes in past climate [4-10]. Different climate proxy time series contain powerful 41-ky ( $1 \mathrm{ky}=1000$ years) oscillation mode during the past $800 \mathrm{ky}$ (Fig.1 from [3], and earlier in the Plio-Pleistocene this mode predominated (Fig. 3 from [3]). In contrast, orbital-scale variations produce, in particular, relatively weak 41-ky power in seasonal insolation (Fig.1 from [3], Fig. 1 from [11]). Estimations based on a climate model of the atmosphere-ocean-sea ice dynamics reveal the strong boreal winter response to the tropical insolation forcing at the precession frequency [11]. Mutual analysis of high-resolution North Atlantic $\delta^{18} \mathrm{O}$ marine sediment records on the other hand, reveals that Late Pleistocene Terminations I and II are "too early to be explained by Northern Hemisphere summer insolation but consistent with changes in Earth's obliquity" [7] (see ibid Fig. 3).

Spectral and wavelet analysis of variations in $\varepsilon$ presented by [12], large explosive volcanic eruptions [13] and the relative content of oxygen-18 in the calcite of fossil benthic foraminifers $\left(\delta^{18} \mathrm{O}_{\mathrm{b}}\right)$ [14] reveal their close phase relationships at the obliquity frequency $[13,15]$. The stable isotopic ratio $\delta^{18} \mathrm{O}_{\mathrm{b}}$ is of special interest since its inverted $\left(-\delta^{18} \mathrm{O}_{\mathrm{b}}\right)$ values reflect the temperature of abyssal ocean waters and sea level changes. Note that the sum of the $-\delta^{18} \mathrm{O}_{\mathrm{b}}$ modes with the periods of 20,41 and $100 \mathrm{ky}$ reproduces its main features over the past 2,000,000 years [15].

A further more-detailed analysis can clarify the role of large explosive volcanic eruptions (VEI $>5$ (Volcanic Explosivity Index)) in the long-term climate changes. To this end below sequential phase relationships of $\varepsilon$ and explosive volcanism $\left(E_{f}\right)$ with $\delta^{18} \mathrm{O}_{\mathrm{b}}$ and other past climate proxy time series are analyzed. It is proposed that powerful 41-ky rhythms in the long-term climate variations can be caused by the geophysical and geochemical effects of the obliquity-induced 41-ky oscillations in large subaerial and seafloor volcanism and magma extrusion. Below, only the 41-ky modes of variations are considered.

\section{Phase Relationships Between $\varepsilon, E_{f}$ and Climate Proxy Data at the Obliquity Frequency}


As was shown in [13] the $E_{f}$ mode lags behind $\varepsilon$ by $2.7 \mathrm{ky}$ over the past 1,200 ky. Wavelet analysis [15] reveals that the $-\delta^{18} \mathrm{O}_{\mathrm{b}}$ mode lags behind $\varepsilon$ by $6.5-7 \mathrm{ky}$. In fact the important conclusion of these two estimations is that the $-\delta^{18} \mathrm{O}_{\mathrm{b}}$ mode lags behind the $E_{f}$ mode at least by $3.8(6.5-2.7=3.8) \mathrm{ky}$. It must be borne in mind that the same data on $\varepsilon$ [12] and $\delta^{18} \mathrm{O}_{\mathrm{b}}[14]$ are used in [13], [15] and this paper. The method of analysis differs: it is spectral analysis in [13], and wavelet analysis in [15] and this paper. Let's now determine the phase lag between $\varepsilon$ and the $-\delta^{18} \mathrm{O}_{\mathrm{b}}$ mode from [13] estimations. Fig. 1 reproduces main features of Fig. 3 from [13]. The $\delta^{18} \mathrm{O}_{\mathrm{b}}$ mode is shifted by $\sim 257^{\circ}$ or -11.8 ky with respect to $\varepsilon$.

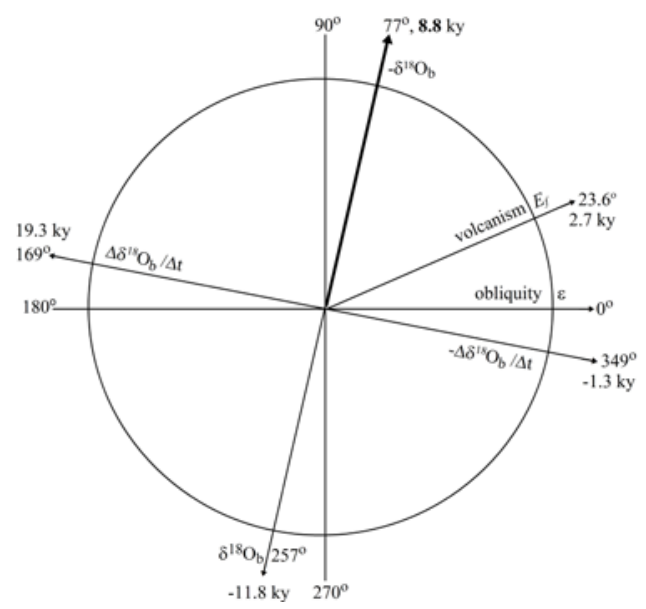

Figure 1. Phase relationships at the period of $41.2 \mathrm{ky}$ between time series of $\delta^{18} \mathrm{O}_{\mathrm{b}}$, the time rate of change of $\delta^{18} \mathrm{O}_{\mathrm{b}}\left(\Delta \delta^{18} \mathrm{O}_{\mathrm{b}} / \mathrm{dt}\right)$, and volcanic eruptions, relative to the Earth's obliquity. The plot reproduces the main features of Figure 3 from [13]. The thick arrow is added to indicate that $-\delta^{18} \mathrm{O}_{\mathrm{b}}$ (abyssal water temperature and sea level proxy) mode lags behind $E_{f}$ (volcanism) mode by $6.1(8.8-2.7) \mathrm{ky}$.

Therefore the $-\delta^{18} \mathrm{O}_{\mathrm{b}}$ mode lags behind $\varepsilon$ by $77^{\circ}\left(257^{\circ}-180^{\circ}\right)$ or $8.8 \mathrm{ky}$ (the thick arrow in Fig. 1 added in comparison with Fig. 3 from [13]. Estimates of the phase shifts between these modes based on spectrum and wavelet technique thus are in accordance. For ice-core data [5, 6] from Antarctica stations (Vostok and Dome C) it is known that their 41-ky modes of variations in carbon dioxide $\left(\mathrm{CO}_{2}\right)$ and methane $\left(\mathrm{CH}_{4}\right)$ concentrations have shifted in phase relative the temperature $(T)$ mode by no more than $1-2$ ky [3].

Table 1 shows phase relationships between $-\delta^{18} \mathrm{O}_{\mathrm{b}}$ and Antarctic and some Greenland climate proxy data from $[5,6,16-18]$.

Table 1. Phase lagging (bold) and correlations at the period of $41 \mathrm{ky}$ between Antarctic and Greenland time series relative to $-\delta^{18} \mathrm{O}_{\mathrm{b}}$. $T$ is the temperature reconstruction, $\mathrm{CO}_{2}, \mathrm{CH}_{4},-\delta^{18} \mathrm{O}_{\text {sea }},-\delta^{18} \mathrm{O}_{\mathrm{atm}}$, Deu, Na, $\mathrm{N}_{2} \mathrm{O}$ are the carbon dioxide, methane, marine and atmospheric $-\delta^{18} \mathrm{O}$, deuterium, natrium, nitrous oxide respectively. The characteristics are ordered in accordance with their significance. L is record length. Vostok data [5], Dome C data [6], Greenland data $[16-18]$.

\begin{tabular}{lccccccccc}
\hline & $\mathrm{T}$ & $\mathrm{CO}_{2}$ & $\mathrm{CH}_{4}$ & Dust & $-\delta^{18} \mathrm{O}_{\text {sea }}$ & $-\delta^{18} \mathrm{O}_{\text {atm }}$ & $\mathrm{Deu}$ & $\mathrm{Na}$ & $\mathrm{N}_{2} \mathrm{O}$ \\
\hline Dome C & $\mathbf{- 1 . 5}$ & $\mathbf{0 . 0}$ & $\mathbf{- 1 . 0}$ & $\mathbf{- 2 . 0}$ & $\mathrm{n} / \mathrm{a}$ & $\mathrm{n} / \mathrm{a}$ & $\mathrm{n} / \mathrm{a}$ & $\mathrm{n} / \mathrm{a}$ & $\mathrm{n} / \mathrm{a}$ \\
$\mathrm{L}=800 \mathrm{ky}$ & +0.95 & +0.81 & +0.92 & -0.76 & & & & & \\
Vostok & $\mathbf{- 0 . 5}$ & $\mathbf{+ 2 . 0}$ & $\mathbf{0 . 0}$ & $\mathbf{0 . 0}$ & $+\mathbf{0 . 5}$ & $\mathbf{+ 2 . 5}$ & $\mathbf{- 0 . 5}$ & $\mathbf{0 . 0}$ & $\mathrm{n} / \mathrm{a}$ \\
$\mathrm{L}=415 \mathrm{ky}$ & +0.90 & +0.90 & +0.89 & -0.77 & +0.91 & +0.75 & 0.90 & -0.90 & \\
Dome C & $\mathbf{- 2 . 0}$ & $\mathbf{- 0 . 5}$ & $\mathbf{- 2 . 0}$ & $\mathbf{- 4 . 0}$ & $\mathrm{n} / \mathrm{a}$ & $\mathrm{n} / \mathrm{a}$ & $\mathrm{n} / \mathrm{a}$ & $\mathrm{n} / \mathrm{a}$ & $\mathrm{n} / \mathrm{a}$ \\
$\mathrm{L}=415 \mathrm{ky}$ & +0.98 & +0.88 & +0.97 & +0.88 & & & & & \\
Greenland & $\mathrm{n} / \mathrm{a}$ & $\mathrm{n} / \mathrm{a}$ & $\mathbf{- 3 . 0}$ & $\mathrm{n} / \mathrm{a}$ & $\mathbf{- 0 . 5}$ & $\mathrm{n} / \mathrm{a}$ & $\mathrm{n} / \mathrm{a}$ & $\mathrm{n} / \mathrm{a}$ & $\mathbf{+ 2 . 0}$ \\
$\mathrm{L}=106 \mathrm{ky}$ & & & +0.98 & & +0.96 & & & & \\
\hline
\end{tabular}


Wavelet based estimates show that phase shifts between the $-\delta^{18} \mathrm{O}_{\mathrm{b}}$ mode and Antarctic climate proxy modes over the past $800 \mathrm{ky}$ do not exceed $2.5 \mathrm{ky}$ (Table 1 ). The $T$ mode, in particular, lags behind the $E_{f}$ one by $2.3 \mathrm{ky}$ and it is dust mode that lags by $1.8 \mathrm{ky}$. (Note that Vostok's $T, \mathrm{CO}_{2}$, $\mathrm{CH}_{4}$, and (inverted) dust modes lag behind corresponding Dome C's modes by $\sim 1.5 \mathrm{ky}$. This indicates the presence of the systematic error in the data timing). Notably, that Dome $\mathrm{C}$ dust mode (over the past $415 \mathrm{ky}$ ) lags behind the $E_{f}$ mode by less than $0.5 \mathrm{ky}$. Table 1 also shows that the $-\delta^{18} \mathrm{O}_{\mathrm{b}}$ mode lags behind the $\mathrm{CH}_{4}$ mode from Greenland ice core by 3 ky over the past 100 ky. All climate proxy modes lag behind the $E_{f}$ mode.

\section{Links Between Orbital-Scale Forcing and Climate Change}

Until recently, the geodynamic factor was not taken into account in the Astronomical theory of longterm climate change $[3,8]$. There is another physical link (Solar system's gravitation) which can produce orbital-scale oscillations in the Earth's body. Recently [19] "determined that SMG (Sun-Moon gravitation)-induced magma motion could produce paleoclimatic variations with multiple periods (e.g., $\sim 23, \sim 40, \sim 80$, and $\sim 100 \mathrm{ky}$ ), with considerable power for Earth's heat". Their dynamic model for SMGinduced magma motion reproduces long-term variations in magma with main frequencies of $1 / 41 \mathrm{ky}^{-1}$ and $1 / 100 \mathrm{ky}^{-1}$. The model curve has more in common with climate proxy curves than correspondent insolation curve (Fig. 1 from [19]). Thus the following chain of cause-and-effect relationships is revealed, as demonstrated by Fig. 2.

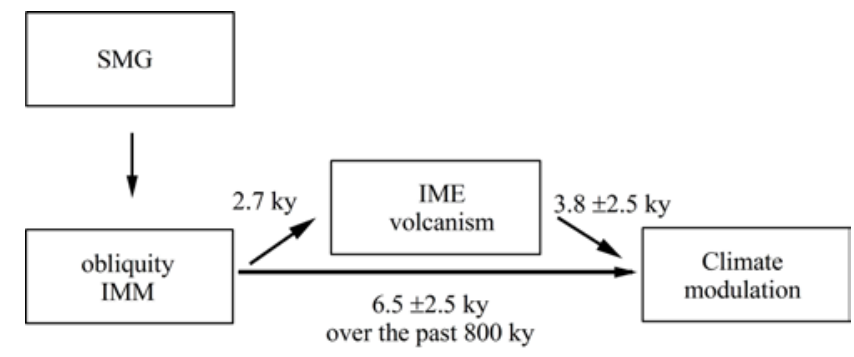

Figure 2. Schematic diagramme of Solar system's effect on the Earth's climate at the period of 41 ky. Sun-Moon gravitation (SMG) produces the Earth's obliquity oscillations $(\varepsilon)$ and SMG-induces magma motion (IMM) (as it is presumed in [19] which generate 41-ky rhythms in variations of seafloor magma extension (IME) and large volcanic activity (volcanism $\left(E_{f}\right)$ ). The $E_{f}$ mode lags behind $\varepsilon$ by $2.7 \mathrm{ky}$ [13]. The $E_{f}$ and IME modes, in turn, produce geophysical and geochemical effects which can cause the 41-ky modulation of ocean temperature, outgoing longwave radiation flux and other climate characteristics. The $-\delta^{18} \mathrm{O}_{\mathrm{b}}$ (deep ocean temperature proxy) mode lags behind $\varepsilon 6.5$ ky as is shown in my previous paper [15]. The $-\delta^{18} \mathrm{O}_{\mathrm{b}}$ mode lags behind the $E_{f}$ mode by $3.8 \mathrm{ky}$, and phase shifts between the $-\delta^{18} \mathrm{O}_{\mathrm{b}}$ mode and Antarctic climate proxy modes do not exceed 2.5 ky (as obtained in present paper).

The 41-ky mode in SMG-induced magma motion [19] and respective variations of magma supply could be detected by multichannel seismic imaging of seafloor highs near mid-ocean ridges (MOR). These rhythms in magma motion in faults could form abyssal hills near MOR. Note else that up-to-date models (see e.g. [20]) consider responses of last millennium climate to both solar irradiance and volcanism but underestimate volcanism (and magma release) impacts on a glacial-interglacial timescale. The study of long-term geophysical and geochemical effects of seafloor magma extrusion and large volcanic eruptions must take into account the geodynamic response to oscillations in obliquity, which would lead to creation of more realistic numerical models of the past climate changes (see e.g. discussion in $[7,8,10])$. New results are in accordance with $[7,11]$ and $[10,19]$, but contradict to the suggestions of [8] and partly [13].

More detailed cross-correlation analysis shows that the $-\delta^{18} \mathrm{O}_{\mathrm{b}}$ mode lags behind $\varepsilon$ by $6.5-7$ ky (correlation coefficient $\mathrm{r}=0.83$ ) over the past $800 \mathrm{ky}$. The lagging of the $-\delta^{18} \mathrm{O}_{\mathrm{b}}$ mode behind $\varepsilon$ increases with ages: in the time interval from $800-1,600$ ky ago it equals 9 ky $(r=0.87)$, and 12 ky $(r=0.93)$ from 2,400 - 3,200 ky ago. Therefore, taking into account the fact that the 41-ky mode dominates in 
the $-\delta^{18} \mathrm{O}_{\mathrm{b}}$ variations during young Pleistocene and Pliocene, one can assume that the consequent phase relationships between $\varepsilon, E_{f}$ and $-\delta^{18} \mathrm{O}_{\mathrm{b}}$ modes are persistent over the past 5,000,000 years.

Reliable data on volcanic activity, igneous rocks chemical composition along with climate proxy indicators could confirm that consequences that are similar to those in Fig. 2 persist over earlier geological time scales. Solar system's gravitation is important factor that impacts the Earth's body at orbital-scale (obliquity and evidently precession) frequencies and can produce geodynamical and geochemical effects and subsequent climate changes.

\section{Remark}

Notably, Kutterolf et al. (2013) wrongly concluded that "the foregoing spectral results strongly suggest that ice-age climate variations induce volcanism" at the obliquity frequency. But that's quite the contrary: according to (Kutterolf et al., 2013) own calculations obliquity and large volcanism induces subsequent climatic effects (e.g. in abyssal water temperature) at the obliquity period, as shown in Fig. 1. (The point is, extrema and zeroes of $-\delta^{18} \mathrm{O}_{\mathrm{b}}$ mode lag behind the corresponding extrema and zeroes of $-\Delta \delta^{18} \mathrm{O}_{\mathrm{b}} / \mathrm{dt}$ mode (which lead volcanism, as authors correctly indicate) by $90^{\circ}$ or $10.3(41.2 / 4)$ $\mathrm{ky})$.

\section{Conclusion}

In the summary, this study demonstrates the validity of the hypothesis that powerful 41-ky rhythms in the Plio-Pleistocene climate changes can be caused by geophysical and geochemical effects (including heat release and greenhouse gases emission) of magma release and large explosive volcanism which is induced by the forced obliquity oscillations. (Variations in ice volume and albedo contribute, in turn, to the increase in the range of climate variability). This new result is based on wavelet and spectral analysis of well known data. It is the step towards the understanding and quantification of orbital-scale impacts (which are not associated with the distribution of solar irradiance) on the geophysical and geochemical processes and climate changes, documented in geological deposits, organic sediments and ice cores.

Acknowledgments. The author is grateful to G. Lohmann for critical comments and suggestions and to G. S. Golitsyn for useful discussions. This work was supported by the Russian Academy of Sciences and by the Russian Foundation for Basic Research, project Nos. 14-05-00639, 16-05-00663. Data used here are properly cited and referred to the reference list and ftp://ftp.ncdc.noaa.gov/pub/data/paleo/ icecore/antarctica/. Corresponding modes are available on request (vabezv@mail.ru).

\section{References}

1. J. A. Adhémar, Revolutions de la mer: Déluges Périodiques, Carilian-Goeury et V. Dalmont, Paris, 1842.

2. J. Croll, Climate and time in their geological relations: a theory of secular changes of theEarth's climate, Edward Stanford, London, 1875.

3. W. H. Berger, Milankovitch theory - hits and misses, Scripps Institution of Oceanography Technical Report, Scripps Institution of Oceanography UC, San Diego, Ca, 2012.

4. K. C. Macdonald, , P. J. Fox, R. T. Alexander, R. Pockalny, P. Gente, "Volcanic growth faults and the origin of Pacific abyssal hills", Nature, vol. 380, pp. 125-129, 1996, doi:10.1038/380125a0.

5. J.R. Petit, I. Basile, A. Leruyuet, D. Raynaud, C. Lorius, J. Jouzel, M. Stievenard, V.Y. Lipenkov, N.I. Barkov, B.B. Kudryashov, M. Davis, E. Saltzman and V. Kotlyakov, "Four climate cycles in Vostok ice core", Nature, vol. 387, pp. 359-360, 1997.

6. EPICA community members, "Eight Glacial Cycles from an Antarctic Ice Core", Nature, vol. 429, pp. 623-628, 2004, doi: 10.1038/nature02599.

7. R. N. C. Drysdale, J. C. Hellstrom, G. Zanchetta, A. E. Fallick, M. F. Sánchez Goñi, I. Couchoud, J. McDonald, R. Maas, G. Lohmann, I. Isola, "Evidence for Obliquity Forcing of Glacial Termination II", Science, vol. 325, no. 5947, pp. 1527-1531, 2009, doi: 10.1126/science.1170371. 
8. J. W. Crowley, R. F. Katz, P. Huybers, C. H. Langmuir, S.-H. Park, "Glacial cycles drive variations in the production of oceanic crust", Science, vol. 347, no. 6227, pp. 1237-1240, 2015, doi:10.1126/science.1261508

9. M. Tolstoy, "Mid-ocean ridge eruptions as a climate valve", Geophysical Research Letters, vol. 42, no. 5, pp. 1346-1351, 2015, doi: 10.1002/2014GL063015.

10. J. A. Goff, "Comment on Glacial cycles drive variations in the production of oceanic crust", Science, vol. 349, no. 6252 , pp. 1065,2015 , doi: $10.1126 /$ science.aab2350

11. G. Lohmann, "Atmospheric bridge on orbital time scales", Theoretical and Applied Climatology, vol. 126, pp. 1-10, 2016, doi: 10.1007/s00704-015-1725-2.

12. A. Berger and M. F. Loutre, "Insolation values for the climate of the last 10 million years", Quaternary Sciences Review, vol. 10, no. 4, pp. 297-317, 1991.

13. S. Kutterolf, M. Jegen, J. X. Mitrovica, T. Kwasnitschka, A. Freundt and P. J. Huybers, "A detection of Milankovitch frequencies in global volcanic activity", Geology, vol. 41, no. 2, pp. 227-230, 2013.

14. L. E. Lisiecki, and M. E. Raymo, "A Pliocene-Pleistocene stack of 57 globally distributed benthic $\delta^{18} \mathrm{O}$ records", Paleoceanography, vol. 20, PA1003, 2005, doi:10.1029/2004PA001071.

15. V. A. Bezverkhnii, "Manifestation of characteristic periods of oscillations of the Earth's orbital parameters in the paleoclimatic data", Doklady Earth Sciences, v. 451, no. 1, pp. 779-783, 2013, doi:10.1134/S1028334X13070209.

16. P.M. Grootes and M. Stuiver, "Oxygen 18/16 variability in Greenland snow and ice with 10^3 to 10^5-year time resolution", Journal of Geophysical Resources, vol. 102, no. C12, pp. 26455-26470, 1997.

17. E. J. Brook, S. Harder, J. Severinghaus, E. J. Steig and C. M. Sucher, "On the origin and timing of rapid changes in atmospheric methane during the Last Glacial Period", Global Biogeochemistry Cycles, vol. 14, no. 2, pp. 559-572, 2000, doi: 10.1029/1999GB001182

18. T. Sowers, R.B. Alley and J. Jubenville, "Ice Core Records of Atmospheric $\mathrm{N}_{2} \mathrm{O}$ Covering the Last 106,000 Years", Science, vol. 301, no. 5635, pp. 945-948, doi: 10.1126/science.1085293.

19. Z. J. Wang and X. Lin, "Astronomy and Climate-Earth System: Can Magma Motion under Sun-Moon Gravitation Contribute to Paleoclimatic Variations and Earth's Heat? ", Advances in Astronomy, vol. 2015, pp. 1-10, 2015. Available: http://dx.doi.org/10.1155/2015/536829.

20. S. Lovejoy and C. Varotsos, "Scaling regimes and linear/nonlinear responses of last millennium climate to volcanic and solar forcings", Earth System Dynamics, vol. 7, no. 1, pp. 133-150, 2016, doi:10.5194/esd-7-133-2016. 